\title{
PEMIMPIN MUDA YANG BERINTEGRITAS MENURUT 1TIMOTIUS 4:12 RELEVANSINYA TERHADAP ALUMNI STT BIBLIKA JAKARTA
}

\author{
Johanes Witoro* \\ Dosen di Sekolah Tinggi Teologi Biblika Jakarta
}

Diterima: 27 Februari 2020; Disetujui: 10 Maret 2020; Dipubliskasikan: 6 April 2020

\begin{abstract}
Abstrak
Pemimpin muda di era globalisasi, bisa saja terjadi di semua kalangan, dari akademisi, pemerintahan, perusahaan dan lain-lain. namun hal itu juga perlu di sadari bahwa, tantangan juga pasti ada untuk pemimpin muda tantangannya yaitu faktor usia, kemudian tanggung jawabnya, pengetahuan, keterampilanya dan kehidupan rohani, serta hal yang lain yaitu, faktor keteladanan dalam perkataan, tingkah laku, dan kesucian hidup. Pendekatan metode kualitatif terhadap pemimpin muda sebagai Alumni STT Biblika Jakarta dari hasil penelitian, telah di temukan bahwa pemimpin muda memiliki pengetahuan dan pemahaman yang sangat baik tentang keilmuan, sebesar $70 \%$ menyatakan kecakapan melakukan kepemimpinan, namun 30\% mereka terkesan ragu-ragu dalam melaksanakan dan untuk keteladanan hidup, secara teori sangat paham namun terkesan ragu-ragu dalam menjaga keteladanan hidup. Dapat disimpulkan bahwa pemimpin muda dibutuhkan keseimbangan antara pengetahuan dan praktek pemimpinnya agar bisa menjadi pemimpin muda yang berintegritas.
\end{abstract}

Kata Kunci: Pemimpin, Muda, Integritas

\begin{abstract}
Young leaders in the era of globalization, it can happen in all walks of life, from academia, government, companies and others. but it also needs to be realized that, challenges also exist for young leaders. The challenges are age, then their responsibilities, knowledge, skills and spiritual life, and other things, exemplary factors in speech, behavior, and sanctity of life. A qualitative method approach to young leaders as Alumni of STT Biblika Jakarta from the results of the study, it was found that young leaders, had very good knowledge and understanding of science and 70\% expressed leadership skills, but 30\% they seemed hesitant in implementing and for exemplary living, in theory are very understanding but seem hesitant in maintaining exemplary living. It can be concluded that young leaders need a balance between the knowledge and practice of their leaders in order to become young leaders with integrity.
\end{abstract}

Keywords: Leader, Young, Integrity

How to Cite: Dr. Johanes Witoro, Th.M. (2020). Pemimpin Muda Yang Berintegritas Menurut 1Timotius 4:12 Relevansinya Terhadap Alumni STT Biblika Jakarta, 5 (1): $13-23$.

*Corresponding author:

ISSN 2355-1704 (Print)

E-mail: johaneswitoro@gmail.com 


\section{PENDAHULUAN}

Impian untuk menjadi pemimpin adalah cita-cita yang mulia, apalagi menjadi pemimpin Kristen dalam pelayanan. Namun pada umumnya usia muda bisa menjadi kendala untuk menjadi pemimpin sehingga Rasul Paulus memberikan nasehat kepada pemimpin muda agar bersikap sesuai dengan ajaran firman Tuhan dalam 1Timotius 4:1-12. Tantangan di dunia modernisasi adalah media online, seperti yang ditulis Johanes Witoro "Peran pemimpin muda yang penting, terutama di era modern ini yang hampir semua kalangan menggunakan media online. Menurut data $80 \%$ pemuda remaja aktif menggunakan media online." Pemimpin muda harus bersifat kooperatif terhadap semua latar belakang budaya, seperti yang ditulis Enny Irawati "perbedaan suku, bahasa, dan budaya dapat mempengaruhi kerukunan."2

Paulus dalam suratnya kepada Timotius menjelaskan bahwa tidak mudah menjadi pemimpin di usia yang muda karena dalam budaya Yahudi usia menjadi salah satu faktor yang diperhitungkan untuk menjadi pemimpin dalam surat 1Timotius 4:1-12. Paulus mensyaratkan kepada Timotius, agar sukses menjadi pemimpin di usia muda. Dari ayat 12 dapat di temukan tabel sebagai berikut.

\begin{tabular}{|c|c|c|}
\hline \multirow{8}{*}{$\begin{array}{l}\text { Pemimpin Muda Yang } \\
\text { Berintegritas Menurut } 1 \\
\text { Timotius } 4: 12\end{array}$} & \multirow{3}{*}{$\begin{array}{l}\text { Memiliki Kualitas } \\
\text { Kepemimpinan Yang Baik } \\
\text { (12a) }\end{array}$} & 1. Memiliki Intelektual \\
\hline & & 2. Memiliki Kecakapan \\
\hline & & $\begin{array}{l}\text { 3. Memiliki Spiritual yang } \\
\text { baik }\end{array}$ \\
\hline & \multirow{5}{*}{ Menjadi Teladan (12b) } & 1. Perkataan \\
\hline & & 2. Tingkah laku \\
\hline & & 3. Kasih \\
\hline & & 4. Kesetiaan \\
\hline & & 5. Kesucian \\
\hline
\end{tabular}

Tabel. 1 Fokus sub-sub focus

\section{METODOLOGI PENELITIAN}

Pendekatan penelitian ini adalah pendekatan penelitian kualitatif analisis taksonomi dengan menggunakan penafsiran Alkitab secara induktif (eksegesa). "Penafsiran Alkitab adalah suatu penelitian Biblika yang bertujuan mengeluarkan makna teks." Untuk mengarahkan perancangan dan pelaksanaan penelitian ini, maka paradigma penelitian adalah paradigma naturalistic. Metode penelitian naturalistic karena penelitian yang dilakukan pada kondisi alamiah, sumber data ialah situasi yang wajar atau "natural setting" peneliti mengumpulkan data berdasarkan observasi situasi yang wajar, sebagaimana adanya, tanpa dipengaruhi dengan sengaja. Peneliti yang memasuki lapangan berhubungan langsung dengan situasi dan orang yang diselidikinya. Paradigma naturalistic atau paradigma alamiah adalah berdasarkan pada sifat fenomenologis. Filsafat fenomenologis ini kemudian dikembangkan dan salah satu perkembanganya diantaranya ialah menjadi metode, yaitu metode fenomenologis.

\footnotetext{
${ }^{1}$ Witoro, Johanes (2019), Peranan Orang Tua Terhadap Tingkat Penggunaan Media Online Remaja di Jakarta (Universitas Negeri Malang: Jurnal Inspirasi Pendidikan, 9, (2), 140

${ }^{2}$ Enny Irawati (2020), Peranan Mahasiswa dan Lembaga dalam Membangun Toleransi Keragaman Budaya di Sekolah Tinggi Teologi Biblika Jakarta, Jurnal Anthropologi Sosial dan Budaya Anthropos, 6 (1), 138 Hidup, 2004)

${ }^{3}$ Andreas Bambang Subagyo, Pengantar Riset Kuantitatif Dan Kualitatif (Bandung: Kalam
} 
“Teknik pengumpulan data yang dipergunakan peneliti adalah: Pertama melakukan tafsir teks Alkitab dengan melakukan pekerjaan eksegesa. Kedua, wawancara dengan informan. Ketiga, membuat analisa penelitian. Wawancara dilakukan dengan metode tertulis yang telah disiapkan sebelumnya yang berisi sejumlah pertanyaan yang akan diajukan kepada informan. Semua kajian dalam penelitian ini adalah Alumni STT Biblika Jakarta."4 Penelitian ini dilakukan di Alummni STT Biblika Jakarta, penelitian ini dilakukan pada tanggal 15-16 Februari 2020.

\section{HASIL EKSEGESA 1TIMOTIUS 4:12}

\section{Pemimpin Muda yang Berintegritas}

1Timotius 4:12, Kata" janganlah seorangpun menganggap engkau rendah" adalah kata kunci penting yang ditunjukan Paulus kepada Timotius, kamu punya potensi dan kualitas yang banyak dan potensi itu bisa menutupi kemudaanmu. Dalam ayat ini mengunakan kata mhdeiz sou thsneutetoz menunjuk kepada nasehat tegas "jangan seorangpun menganggap engkau rendah" mengungkapkan tentang adanya potensi Timotius dalam memimpin Memiliki karakter yang baik Dalam ayat 6 "pelayanan Kristus yang baik" kemudaan akan dapat tertutupi oleh karena karekter yang baik. Dalam Bahasa asli mengunakan "kalos"6 adalah karakter yang dominan dimiliki pelayan Kristus.

A. Pemimpin muda yang berkualitas

1. Memiliki Intelektual yang baik

Dalam ayat 6, menyebutkan "terdidik" merupakan kualifikasi pemimpin yang sangat penting, terutama "terdidik" berasal dari kata "entrepomenos"7 artinya terdidik tentang pokok-pokok Iman Kristen. Sama halnya dengan seorang yang terpelajar atau berpengetahuan yang baik tentang pokok-pokok iman.

2. Memiliki Kecakapan

Dalam ayat 2-3, adanya masalah yang komplek dalam jemaat di Efesus, pengajaran Palsu atau sesat mempengaruhi kehidupan iman jemaat, disini peran Pemimpin muda harus menunjukkan kemampuan dalam menyelesaikan masalah. "Jauhilah tahayul" menunjukkan suatu perintah bagi seorang pemimpin yang memiliki pengetahuan dan berpegang pada pokok iman harus memiliki kecakapan dalam mengatasi masalah.

3. Memiliki Spiritulalitas yang baik

Dalam nasehatnya Paulus menekankan bahwa latihan badani itu sangat penting namun terbatas manfaatnya, namun latihan rohani tidak terbatas (ayat 7) berguna untuk hidup didunia saat ini tetapi juga ketika kita meninggal dunia. Kata $(\text { eusebeian })^{8}$ artinya kesalehan itu berguna saat ini tetapi juga masa depan.

${ }^{4}$ Lexy J. Moleong, Metodologi Penelitian Kualitatif (Bandung: PT Remaja Rosdakarya,

\footnotetext{
${ }^{5}$ Alkitab. Terjemahan baru 1 Timotius 4:6

${ }^{6}$ LAI, Perjanian Baru Interlinier Yunani-Indonesia, (Jakarta, LAI, Cetakan 2, 2004), 1116.

${ }^{7}$ Ibid.

${ }^{8}$ Ibid.
} 
B. Pemimpin Muda yang Menjadi Teladan

1. Menjadi teladan dalam Perkataanmu $(\operatorname{lego})^{9}$ kemampuan menguasai diri dalam berkata-kata jika pemimpin memiliki kemampuan untuk mengucapkan kata-kata yang bermanfaat dan berguna saja.

2. Menjadi teladan dalam tingkah lakumu (anatrofe $\left.e^{10}\right)^{11}$ dalam alkitab NIV (in life) bermaksud prilaku kehidupan sehari-hari menjadi tekanan Paulus, kejatuhan pemimpin muda, prilaku kemudaan dan emosional, serta hidup keduniawian menjadi pantauan penting bagi seorang pemimpin.

3. Menjadi teladan dalam kasihmu, (in Love) kasih menjadi gaya hidup orang percaya dan tidak mudah untuk dilakukan, Paulus mengunakan (en agaphe) ${ }^{12}$ kasih yang dipakai adalah kasih Allah yang penuh kerelaan dan tanpa pamrih.

4. Menjadi teladan dalam Kesetiaanmu, kesetiaan apa yang dimaksud Paulus, ternyata yang dimaksudkan (en pistei) ${ }^{13}$ bisa memiliki dua pengertian yaitu "kestiaan" tetapi juga "iman" namun sesungguhnya keduanya tidak bisa dipisahkan, orang yang beriman sebagai seorang muda juga dituntut setia, dalam segala hal.

5. Menjadi teladan dalam kesuciaanmu, kata (agneia) ${ }^{14}$ lebih tepat diterjemahkan sebagai "kemurnian" atau juga "kesucian" dua hal yang tidak mudah dipertahankan sebagai pemimpin muda, pengaruh besar dalam hidup pemimpin muda yaitu, dosa percabulan dan seksual, dapat menghancurkan kepemimpinan rohani.

\section{HASIL DAN PEMBAHSAN}

1. Pemimpin yang berkualitas

\begin{tabular}{|c|c|c|c|c|}
\hline \multirow{2}{*}{ No } & \multicolumn{4}{|c|}{ Pemimpin Muda yang Berkualitas } \\
\hline & Berintegritas & Intelektual & Cakap & Spiritualitas \\
\hline 1 & $\begin{array}{l}\text { Pemimpin yang } \\
\text { berintegritas adalah } \\
\text { pemimpin yang dapat } \\
\text { dipercaya, karena } \\
\text { memiliki keselarasan } \\
\text { antara perkataan } \\
\text { dengan } \\
\text { perbuatanya/tindakann } \\
\text { ya. Selalu } \\
\text { berkomitmen untuk } \\
\text { mengerjakan atau } \\
\text { menyelesaikan apa } \\
\text { yang telah di ucapkan } \\
\text { atau janjikan }\end{array}$ & $\begin{array}{l}\text { Pemimpin muda } \\
\text { harus berintelektual } \\
\text { supaya tidak } \\
\text { diremehkan dan } \\
\text { direndahkan oleh } \\
\text { orang lain dan dapat } \\
\text { memimpin/membimb } \\
\text { ing orang lain untuk } \\
\text { diarahkan mencapai } \\
\text { suatu tujuan sesuai } \\
\text { yang telah } \\
\text { dirancang/ditetapkan } \\
\text { sebelumnya. }\end{array}$ & $\begin{array}{l}\text { Karena dalam sebuah } \\
\text { kepemimpinan tidak } \\
\text { akan mungkin } \\
\text { terlepas dari } \\
\text { persoalan dan } \\
\text { tantangan, baik dari } \\
\text { dalam maupun dari } \\
\text { luar, sehingga dengan } \\
\text { kecakapan yang } \\
\text { dimiliki akan dapat } \\
\text { menemukan solusi } \\
\text { dari setiap persoalan } \\
\text { atau tantangan yang } \\
\text { dihadapi. }\end{array}$ & $\begin{array}{l}\text { Spiritualitas yang } \\
\text { baik menjadi } \\
\text { salah satu syarat } \\
\text { yang paling } \\
\text { utama, bagi } \\
\text { seorang pemimpin } \\
\text { apalagi pemimpin } \\
\text { Kristen, dengan } \\
\text { Spriritualitas yang } \\
\text { baik maka akan } \\
\text { selalu } \\
\text { mendapatkan } \\
\text { hikmat dalam } \\
\text { berkata-kata dan } \\
\text { bertindak, } \\
\text { sehingga dalam } \\
\text { menjalankan } \\
\text { kepemimpinan } \\
\text { akan sesuai }\end{array}$ \\
\hline
\end{tabular}

\footnotetext{
${ }^{9}$ Ibid.

${ }^{10}$ Ibid.

${ }^{11}$ Ibid.

${ }^{12}$ Ibid.

${ }^{13}$ Ibid.

${ }^{14}$ Ibid.
} 


\begin{tabular}{|c|c|c|c|c|}
\hline & & & & $\begin{array}{l}\text { dengan Firman } \\
\text { Tuhan }\end{array}$ \\
\hline 2 & $\begin{array}{l}\text { Memiliki tanggung- } \\
\text { jawab besar dalam } \\
\text { kepemimpinannya } \\
\text { memiliki teladan yang } \\
\text { patut ditiru, melalui } \\
\text { perkataan, tingkah } \\
\text { laku serta gaya hidup } \\
\text { yang baik }\end{array}$ & $\begin{array}{l}\text { Ya, sangat penting. } \\
\text { Karena seorang } \\
\text { pemimpin dituntut } \\
\text { untuk memiliki } \\
\text { inisiatif dalam segala } \\
\text { hal. }\end{array}$ & $\begin{array}{l}\text { Ya, karena seorang } \\
\text { pemimpin harus } \\
\text { mampu memecahkan } \\
\text { hal-hal yang menjadi } \\
\text { kendala atas } \\
\text { persoalan. Harus } \\
\text { mampu memberi } \\
\text { solusi dalam kondisi } \\
\text { yang terjadi }\end{array}$ & $\begin{array}{l}\text { Ya, sangat } \\
\text { penting. Karena } \\
\text { Spiritualitas yang } \\
\text { baik sangat } \\
\text { berdampak atas } \\
\text { pribadi seorang } \\
\text { pemimpin. }\end{array}$ \\
\hline 3 & $\begin{array}{l}\text { Pemimpin yang } \\
\text { menunjukkan kualitas } \\
\text { bicara dengan } \\
\text { tindakannya yang } \\
\text { sesuai sehingga } \\
\text { menjadi pengaruh bagi } \\
\text { pengikutnya. }\end{array}$ & $\begin{array}{l}\text { Dengan memiliki } \\
\text { intelektual yang baik } \\
\text { maka pemimpin akan } \\
\text { menunjukan } \\
\text { kualitasnya sehingga } \\
\text { akan menimbulkan } \\
\text { terobosan-terobosan } \\
\text { baru bagi lembaga. }\end{array}$ & $\begin{array}{l}\text { Adanya masalah } \\
\text { yang dapat } \\
\text { diselesaikan akan } \\
\text { membuat pemimpin } \\
\text { muda semakin berani } \\
\text { untuk dipercaya } \\
\text { dalam hal besar. } \\
\text { Sehingga akan } \\
\text { terlihat kualitasnya } \\
\text { dalam memimpin }\end{array}$ & $\begin{array}{l}\text { Spiritualitas yang } \\
\text { baik akan } \\
\text { menunjukkan } \\
\text { tingkah yang baik, } \\
\text { sehingga dalam } \\
\text { kepemimpinannya } \\
\text { akan menjadi } \\
\text { pengaruh yang } \\
\text { baik }\end{array}$ \\
\hline 4 & $\begin{array}{l}\text { Pemimpin yang } \\
\text { berintegritas adalah } \\
\text { pemimpin yang bisa } \\
\text { bertanggung jawab } \\
\text { dalam segala hal dan } \\
\text { memegang penuh } \\
\text { dalam pedoman- } \\
\text { pedoman yang ada } \\
\text { terutama dalam } \\
\text { Alkitab }\end{array}$ & $\begin{array}{l}\text { Karena sangat } \\
\text { diperlukan dalam } \\
\text { saat-saat ini supaya } \\
\text { bisa melawan } \\
\text { perubahan-perubahan } \\
\text { yang lebih baik dan } \\
\text { bisa bersaing dengan } \\
\text { yang lain. }\end{array}$ & $\begin{array}{l}\text { Karena pemimpin } \\
\text { muda bisa belajar } \\
\text { menyelesaikan } \\
\text { masalah dengan tepat }\end{array}$ & $\begin{array}{l}\text { Karena tanpa } \\
\text { spiritual yang baik } \\
\text { seorang } \\
\text { Pemimpin tidak } \\
\text { bisa } \\
\text { menyelesaikan } \\
\text { masalah dengan } \\
\text { tepat. }\end{array}$ \\
\hline 5 & $\begin{array}{l}\text { Pemimpin yang } \\
\text { berintegritas adalah } \\
\text { pemimpin yang } \\
\text { konsekuen dengan apa } \\
\text { yang dikatakan sesuai } \\
\text { dengan apa yang } \\
\text { dilakukan }\end{array}$ & $\begin{array}{l}\text { Supaya tidak } \\
\text { direndahkan orang }\end{array}$ & $\begin{array}{l}\text { Karena dengan } \\
\text { kecakapan yang } \\
\text { dimiliki, orang lain } \\
\text { mempercayai kita }\end{array}$ & $\begin{array}{l}\text { Karena spiritual } \\
\text { menentukan } \\
\text { kecakapan dalam } \\
\text { intelektual } \\
\text { seseorang (Amsal } \\
1: 7 \text { ) }\end{array}$ \\
\hline 6 & $\begin{array}{l}\text { Pemimpin } \\
\text { menunjukkan sikap } \\
\text { konsisten antara } \\
\text { ucapan dan tindakan } \\
\text { yang dikerjakan atau } \\
\text { dilakukan yang } \\
\text { tercermin dalam } \\
\text { kehidupan dan } \\
\text { perbuatan setiap hari. }\end{array}$ & $\begin{array}{l}\text { Karena } \\
\text { kepemimpinan yang } \\
\text { diimbangi dengan } \\
\text { intelektual yang } \\
\text { dimiliki akan sulit } \\
\text { untuk } \\
\text { mempertahankan, } \\
\text { mengembangkan dan } \\
\text { menjalankan suatu } \\
\text { visi dan misi yang } \\
\text { dikerjakan. Dengan } \\
\text { intelektual dan } \\
\text { ketentuan yang } \\
\text { dimiliki seorang } \\
\text { pemimpin maka akan } \\
\text { sangat membantu } \\
\text { untuk mengerjakan } \\
\text { dan membuat } \\
\text { program }\end{array}$ & $\begin{array}{l}\text { Karna seorang } \\
\text { pemimpin tidak } \\
\text { hanya cukup } \\
\text { bertindak sebagai } \\
\text { pemberi tugas, } \\
\text { mandat atau perintah } \\
\text { kepada bawahanya } \\
\text { mengenai sesuatu } \\
\text { yang harus } \\
\text { dikerjakan tetapi juga } \\
\text { harus mampu } \\
\text { menyelesaikan } \\
\text { masalah yang } \\
\text { dihadapi dan ini } \\
\text { membuktikan bahwa } \\
\text { seseorang pemimpin } \\
\text { memiliki kualitas. } \\
\text { Selain itu juga } \\
\text { bertanggung jawab } \\
\text { dan dapat dipercaya }\end{array}$ & $\begin{array}{l}\text { Karena dengan } \\
\text { spiritualitas hidup } \\
\text { yang baik, maka } \\
\text { akan dapat } \\
\text { mengontrol } \\
\text { seorang pemimpin } \\
\text { di dalam bersikap } \\
\text { atau bertindak di } \\
\text { dalam } \\
\text { kepemimpinanya. }\end{array}$ \\
\hline
\end{tabular}




\begin{tabular}{|c|c|c|c|c|}
\hline & & & dalam memimpin. & \\
\hline 7 & $\begin{array}{l}\text { Pemimpin yang } \\
\text { berintegritas adalah } \\
\text { pemimpin bisa } \\
\text { dipercaya dan hidup } \\
\text { penuh kejujuran. }\end{array}$ & $\begin{array}{l}\text { Dunia semakin } \\
\text { berkembang } \\
\text { diberbagai bidang } \\
\text { dan selalu ada } \\
\text { perubahan untuk itu } \\
\text { dibutuhkan pemimpin } \\
\text { yang penuh wawasan } \\
\text { luas secara } \\
\text { global/intelektual }\end{array}$ & $\begin{array}{l}\text { Kriteria seorang } \\
\text { pemimpin adalah } \\
\text { cakap menyelesaikan } \\
\text { masalah dengan itu ia } \\
\text { mampu diberi } \\
\text { tanggung jawab }\end{array}$ & $\begin{array}{l}\text { Karena dengan } \\
\text { memiliki } \\
\text { spiritualitas yang } \\
\text { baik, ia tahu } \\
\text { bagaimana cara } \\
\text { memimpin } \\
\text { dengan benar. } \\
\text { Spiritualitas } \\
\text { menajdi dasar } \\
\text { kepemimpinanya. }\end{array}$ \\
\hline
\end{tabular}

Tabel. 2. Pemimpin Yang Berkualitas

2. Pemimpin muda yang menjadi teladan

\begin{tabular}{|c|c|c|c|c|c|c|}
\hline $\mathrm{N}$ & \multicolumn{6}{|c|}{ Pemimpin muda yang menjadi teladan } \\
\hline $\mathrm{O}$ & Teladan & Perkataan & Tingkah laku & Kasih & Kesetiaan & Kesucian \\
\hline 1 & $\begin{array}{l}\text { Menjadi } \\
\text { teladan } \\
\text { berarti } \\
\text { menjadi } \\
\text { contoh atau } \\
\text { model bagi } \\
\text { orang } \\
\text { lain,baik } \\
\text { dalam } \\
\text { perkataan } \\
\text { maupun } \\
\text { dalam } \\
\text { tindakan, } \\
\text { untuk } \\
\text { menjadi } \\
\text { teladan usia } \\
\text { bukanlah } \\
\text { sebagai } \\
\text { patokan, } \\
\text { sekalipun } \\
\text { masih muda } \\
\text { tetapi harus } \\
\text { menajdi } \\
\text { teladan yang } \\
\text { baik, } \\
\text { sehingga } \\
\text { akan selalu } \\
\text { diikuti oleh } \\
\text { orang } \\
\text { lain/jemaat }\end{array}$ & $\begin{array}{l}\text { Sebagai } \\
\text { seorang } \\
\text { pemimpin } \\
\text { harus dapat } \\
\text { dipegang atau } \\
\text { di percayakan } \\
\text { kata-katanya, } \\
\text { dan juga harus } \\
\text { memperkata } \\
\text { kan yang baik. } \\
\text { Dengan begitu } \\
\text { seorang } \\
\text { pemimpin } \\
\text { akan dapat } \\
\text { menjalankan } \\
\text { kepemimpinan } \\
\text { ya dengan baik } \\
\text { dan terus } \\
\text { menjadi } \\
\text { teladan bagi } \\
\text { para } \\
\text { pengikutnya. }\end{array}$ & $\begin{array}{l}\text { Tingkah laku } \\
\text { seorang } \\
\text { pemimpin } \\
\text { sangat } \\
\text { menentukan } \\
\text { keberhasilan } \\
\text { dalam } \\
\text { kepemimpinany } \\
\text { a. Jika memiliki } \\
\text { tingkah laku } \\
\text { yang baik maka } \\
\text { pasti akan dapat } \\
\text { berhasil dalam } \\
\text { memimpin, } \\
\text { tetapi } \\
\text { sebaliknya jika } \\
\text { tingkah lakunya } \\
\text { seorang } \\
\text { pemimpin tidak } \\
\text { baik maka } \\
\text { kepemimpinany } \\
\text { a akan hancur. } \\
\text { Terlebih-lebih } \\
\text { bagi seorang } \\
\text { pemimpin muda } \\
\text { yang mungkin } \\
\text { bagi sebagian } \\
\text { orang masih } \\
\text { dianggap belum } \\
\text { dewasa dalam } \\
\text { bertindak }\end{array}$ & $\begin{array}{l}\text { Seorang } \\
\text { pemimpin } \\
\text { muda harus } \\
\text { memiliki kasih } \\
\text { supaya dapat } \\
\text { berempati } \\
\text { dengan orang } \\
\text { lain, terlebih- } \\
\text { lebih orang } \\
\text { yang } \\
\text { dipimpinnya. } \\
\text { Seorang } \\
\text { pemimpin } \\
\text { Rohani harus } \\
\text { memiliki kasih } \\
\text { yang luar biasa } \\
\text { terhadap orang } \\
\text { lain, karena } \\
\text { Tuhan Yesus } \\
\text { yang telah } \\
\text { memberikan } \\
\text { contoh dan } \\
\text { teladan dalam } \\
\text { mengasihi, } \\
\text { maka } \\
\text { pemimpin } \\
\text { Kristen harus } \\
\text { mengikuti } \\
\text { teladan } \\
\text { tersebut }\end{array}$ & $\begin{array}{l}\text { Pemimpin } \\
\text { muda } \\
\text { terkadang } \\
\text { masih } \\
\text { dianggap } \\
\text { masih labil } \\
\text { dan } \\
\text { gampang } \\
\text { berubah, } \\
\text { tetapi } \\
\text { kesetiaan } \\
\text { dalam } \\
\text { memimpin } \\
\text { akan } \\
\text { menentuka } \\
\mathrm{n} \\
\text { perjalanan } \\
\text { sebah } \\
\text { lembaga } \\
\text { organisasi } \\
\text { yang } \\
\text { dipimpin } \\
\text { memimpin } \\
\text { dengan } \\
\text { setia maka } \\
\text { akan dapat } \\
\text { membawa } \\
\text { kepada } \\
\text { suatu } \\
\text { tingkat } \\
\text { keberhasila } \\
\mathrm{n} \text { yan baik }\end{array}$ & $\begin{array}{l}\text { Pemimpinan } \\
\text { muda harus } \\
\text { memiliki } \\
\text { kesucian } \\
\text { hidup karena } \\
\text { kesucian } \\
\text { hidup } \\
\text { seorang } \\
\text { pemimpin } \\
\text { menjadi } \\
\text { kunci } \\
\text { keberhasilan } \\
\text { seorang } \\
\text { pemimpin } \\
\text { tanpa } \\
\text { kesucian } \\
\text { hidup } \\
\text { kepemimpin } \\
\text { an seseorang } \\
\text { akan hancur } \\
\text { berantakan, } \\
\text { Tuhan juga } \\
\text { tidak akan } \\
\text { berkenan } \\
\text { kepada yang } \\
\text { tidak } \\
\text { memiliki } \\
\text { kesucian } \\
\text { hidup, dan } \\
\text { akan } \\
\text { ditinggalkan } \\
\text { oleh orang- } \\
\text { orang yang } \\
\text { dipimpinnya }\end{array}$ \\
\hline 2 & $\begin{array}{l}\text { Teladan } \\
\text { merupakan } \\
\text { patron yang } \\
\text { patut di } \\
\text { tiru/dicontoh }\end{array}$ & $\begin{array}{l}\text { Perkataan } \\
\text { merupakan hal } \\
\text { terpenting } \\
\text { dalam } \\
\text { kepemimpinan } \\
\text {, yang }\end{array}$ & $\begin{array}{l}\text { Tingkah laku } \\
\text { merupakan } \\
\text { tindakan nyata } \\
\text { seseorang, yang } \\
\text { menggambarka } \\
\text { n perilaku hidup }\end{array}$ & $\begin{array}{l}\text { merupakan } \\
\text { dasar dari } \\
\text { segala } \\
\text { keputusan } \\
\text { tindakan dan }\end{array}$ & $\begin{array}{l}\text { Karena } \\
\text { kesetiaan } \\
\text { mewakili } \\
\text { pribadi } \\
\text { seseorang } \\
\text { dalam }\end{array}$ & $\begin{array}{l}\text { Karena } \\
\text { kesucian } \\
\text { mencermink } \\
\text { an iman } \\
\text { rohani } \\
\text { seseorang }\end{array}$ \\
\hline
\end{tabular}


Jurnal Teologi Biblika, Vol. 5, No. 1, Edisi April 2020

Johanes Witoro, Pemimpin Muda yang Berintegritas Menurut 1Timotius 4:12 Relevansinya Terhadap

Alumni STT Biblika Jakarta

Hal: 13-23

\begin{tabular}{|c|c|c|c|c|c|c|}
\hline & & $\begin{array}{l}\text { menggambark } \\
\text { an sifat dan } \\
\text { pribadi } \\
\text { seseorang }\end{array}$ & seseorang & $\begin{array}{l}\text { pola hidup } \\
\text { seseorang }\end{array}$ & $\begin{array}{l}\text { kondisi } \\
\text { situasi } \\
\text { tertentu }\end{array}$ & \\
\hline 3 & $\begin{array}{l}\text { Menjadi } \\
\text { teladan } \\
\text { merupakan } \\
\text { tindakan } \\
\text { yang } \\
\text { dilakukan } \\
\text { supaya } \\
\text { orang lain } \\
\text { juga } \\
\text { melakukan }\end{array}$ & $\begin{array}{l}\text { Perkataan } \\
\text { merupakan ciri } \\
\text { seorang } \\
\text { pemimpin } \\
\text { yang memiliki } \\
\text { intelektual } \\
\text { yang baik, } \\
\text { melalui } \\
\text { perkataannya } \\
\text { akan membuat } \\
\text { orang lain } \\
\text { bertumbuh }\end{array}$ & $\begin{array}{l}\text { Pemimpin yang } \\
\text { baik akan } \\
\text { menunjukkan } \\
\text { tingkah laku } \\
\text { yang baik. } \\
\text { Sehingga akan } \\
\text { mencerminkan } \\
\text { kualitas } \\
\text { pemimpin yang } \\
\text { dapat menjadi } \\
\text { teladan bagi } \\
\text { para } \\
\text { pengikutnya }\end{array}$ & $\begin{array}{l}\text { Dengan } \\
\text { adanya kasih } \\
\text { dalam hati } \\
\text { seorang } \\
\text { pemimpin } \\
\text { maka } \\
\text { pemimpin } \\
\text { tersebut akan } \\
\text { bertindak } \\
\text { dengan hati } \\
\text { sehingga tidak } \\
\text { akan membuat } \\
\text { pengikutnya } \\
\text { sakit hati. } \\
\text { Kasih } \\
\text { mencerminkan } \\
\text { seorang } \\
\text { pemimpin } \\
\text { yang } \\
\text { berkualitas. }\end{array}$ & $\begin{array}{l}\text { Tanpa } \\
\text { kesetiaan } \\
\text { seorang } \\
\text { pemimpin } \\
\text { tidak akan } \\
\text { dapat } \\
\text { memimpin } \\
\text { suatu } \\
\text { organisasi. } \\
\text { Karna } \\
\text { kesetiaan } \\
\text { akan } \\
\text { membuat } \\
\text { seorang } \\
\text { pemimpin } \\
\text { berhasil } \\
\text { dalam } \\
\text { segala } \\
\text { sesuatu } \\
\text { yang } \\
\text { dipimpinya }\end{array}$ & $\begin{array}{l}\text { karna } \\
\text { kesucian } \\
\text { menunjukka } \\
\text { n seorang } \\
\text { pemimpin } \\
\text { yang tegas } \\
\text { dalam } \\
\text { pendirian } \\
\text { sehingga } \\
\text { tidak mudah } \\
\text { terpengaruh } \\
\text { oleh hal-hal } \\
\text { yang jahat } \\
\text { yang bisa } \\
\text { merusak } \\
\text { hubunganya } \\
\text { dengan } \\
\text { Tuhan dan } \\
\text { manusia. } \\
\text { Pemimpin } \\
\text { yang } \\
\text { memiliki } \\
\text { kesucian } \\
\text { yang baik } \\
\text { tidak mudah } \\
\text { juga } \\
\text { dijatuhkan } \\
\text { oleh orang } \\
\text { lain. Yang } \\
\text { ingin } \\
\text { merebut } \\
\text { kepemimpin } \\
\text { anya } \\
\end{array}$ \\
\hline 4 & $\begin{array}{l}\text { Teladan } \\
\text { adalah } \\
\text { menjadi } \\
\text { contoh atau } \\
\text { berkat bagi } \\
\text { anggotanya }\end{array}$ & $\begin{array}{l}\text { Karena } \\
\text { melalui } \\
\text { perkataan } \\
\text { seorang } \\
\text { pemimpin bisa } \\
\text { dilihat } \\
\text { kapasitasnya } \\
\text { sebagai } \\
\text { pemimpin atau } \\
\text { tidak }\end{array}$ & $\begin{array}{l}\text { Karena tingkah } \\
\text { laku } \\
\text { menunjukkan } \\
\text { perilakunya } \\
\text { apakah baik } \\
\text { atau buruk }\end{array}$ & $\begin{array}{l}\text { Karena tanpa } \\
\text { kasih } \\
\text { pemimpin bisa } \\
\text { otoriter }\end{array}$ & $\begin{array}{l}\text { Kesetiaan } \\
\text { pemimpin } \\
\text { akan sangat } \\
\text { berpengaru } \\
\text { h terhadap } \\
\text { anggotanya }\end{array}$ & $\begin{array}{l}\text { Karena } \\
\text { seorang } \\
\text { pemimpin } \\
\text { tidak boleh } \\
\text { dipengaruhi } \\
\text { dengan yang } \\
\text { jahat }\end{array}$ \\
\hline 5 & $\begin{array}{l}\text { Teladan } \\
\text { (tupos) } \\
\text { adalah } \\
\text { pola/patron } \\
\text { bagi orang } \\
\text { lain dalam } \\
\text { bersikap, } \\
\text { bertindak } \\
\text { dan } \\
\text { melakukan } \\
\text { segala } \\
\end{array}$ & $\begin{array}{l}\text { Supaya kita } \\
\text { menjadi } \\
\text { contoh teladan } \\
\text { bagi orang } \\
\text { lain, sehingga } \\
\text { orang lain } \\
\text { dapat } \\
\text { bertumbuh dan } \\
\text { mengenal } \\
\text { Allah melalui } \\
\text { perkataan kita }\end{array}$ & $\begin{array}{l}\text { Pemimpin harus } \\
\text { memiliki } \\
\text { tingkah laku } \\
\text { yang baik agar } \\
\text { orang lain dapat } \\
\text { melihat kristus } \\
\text { dalam hidup } \\
\text { kita ( } 2 \text { Korintus } \\
3: 2 \text { ) }\end{array}$ & $\begin{array}{l}\text { Karena kasih } \\
\text { adalah sifat } \\
\text { dasar } \\
\text { Allah,karena } \\
\text { itu sebagai } \\
\text { seorang } \\
\text { pemimpin } \\
\text { mesti memiliki } \\
\text { karakter dan } \\
\text { sifat Allah } \\
\text { yang sangat }\end{array}$ & $\begin{array}{l}\text { Karena } \\
\text { kesetiaan } \\
\text { adalah } \\
\text { tolak ukur } \\
\text { seseorang } \\
\text { dalam } \\
\text { memimpin, } \\
\text { karena } \\
\text { tanpa } \\
\text { kesetiaan } \\
\text { seseorang }\end{array}$ & $\begin{array}{l}\text { Karena } \\
\text { tanpa } \\
\text { kesucian } \\
\text { kita tidak } \\
\text { dapat } \\
\text { melayani } \\
\text { Allah (Ibr } \\
\text { 12:14) }\end{array}$ \\
\hline
\end{tabular}


Jurnal Teologi Biblika, Vol. 5, No. 1, Edisi April 2020

Johanes Witoro, Pemimpin Muda yang Berintegritas Menurut 1Timotius 4:12 Relevansinya Terhadap

Alumni STT Biblika Jakarta

Hal: $13-23$

\begin{tabular}{|c|c|c|c|c|c|c|}
\hline & $\begin{array}{l}\text { sesuatu yang } \\
\text { lain. }\end{array}$ & $\begin{array}{l}\text { apa yang kita } \\
\text { lakukan } \\
\text { mencerminkan } \\
\text { siapa diri kita. }\end{array}$ & & $\begin{array}{l}\text { mendasar (1 } \\
\text { Yohanes 2:6) }\end{array}$ & $\begin{array}{l}\text { tidak dapat } \\
\text { memimpin }\end{array}$ & \\
\hline 6 & $\begin{array}{l}\text { Menjadi } \\
\text { teladan ialah } \\
\text { menjadi } \\
\text { contoh, } \\
\text { panutan dan } \\
\text { miliki sikap } \\
\text { yang baik } \\
\text { atau dapat } \\
\text { menjaga } \\
\text { sikap } \\
\text { karakter } \\
\text { yangbaik } \\
\text { dimanapun } \\
\text { ia berada }\end{array}$ & $\begin{array}{l}\text { Seorang } \\
\text { pemimpin } \\
\text { memiliki } \\
\text { perkataan yang } \\
\text { baik akan } \\
\text { sangat di } \\
\text { hormati dan di } \\
\text { hargai oleh } \\
\text { orang-orang } \\
\text { yang ada } \\
\text { disekelilingnya } \\
\text {. }\end{array}$ & $\begin{array}{l}\text { Sikap atau } \\
\text { tingkah laku } \\
\text { merupakan } \\
\text { suatu hal yang } \\
\text { sangat penting } \\
\text { bagi seseorang } \\
\text { pemimpin agar } \\
\text { dihargai, di } \\
\text { hormati, } \\
\text { disegani dan } \\
\text { dijadikan } \\
\text { contoh oleh } \\
\text { bawahanya. }\end{array}$ & $\begin{array}{l}\text { Karena } \\
\text { pemimpin } \\
\text { yang di dasari } \\
\text { dengan kasih } \\
\text { akan dapat } \\
\text { menjalankan } \\
\text { tugasnya } \\
\text { dengan } \\
\text { pertimbangan } \\
\text { dari sikap } \\
\text { peduli dengan } \\
\text { orang lain ada } \\
\text { di bawah } \\
\text { kepemimpinan } \\
\text { nya. Dia turut } \\
\text { merasakan apa } \\
\text { yang orang } \\
\text { lain rasakan } \\
\text { dan ia akan } \\
\text { dapat } \\
\text { merangkaul } \\
\text { orang lain } \\
\text { dalam } \\
\text { menjalankan } \\
\text { tugasnya }\end{array}$ & $\begin{array}{l}\text { Karena } \\
\text { dalam } \\
\text { menjalanka } \\
\text { n tugasnya } \\
\text { sebagai } \\
\text { seorang } \\
\text { pemimpin } \\
\text { jika tidak } \\
\text { setia, maka } \\
\text { hal apapun } \\
\text { yang } \\
\text { dilakukan/d } \\
\text { ikerjakan } \\
\text { akan } \\
\text { hancur } \\
\text { berantakan } \\
\text { dan segala } \\
\text { visi misi } \\
\text { setiap } \\
\text { program } \\
\text { yang telah } \\
\text { di } \\
\text { rencanakan } \\
\text { tidak bisa } \\
\text { dilaksanaka } \\
\text { n dengan } \\
\text { baik. }\end{array}$ & $\begin{array}{l}\text { Karena } \\
\text { seorang } \\
\text { pemimpin } \\
\text { adalah } \\
\text { sebagai } \\
\text { contoh, } \\
\text { panutan dan } \\
\text { teladan yang } \\
\text { selalu di } \\
\text { lihat dan } \\
\text { diperhatikan } \\
\text { oleh orang } \\
\text { lain }\end{array}$ \\
\hline 7 & $\begin{array}{l}\text { Menjadi } \\
\text { teladan } \\
\text { adalah } \\
\text { bahwa } \\
\text { seorang } \\
\text { pemimpin } \\
\text { tersebut } \\
\text { sudah } \\
\text { melakukan/ } \\
\text { menghidupi } \\
\text { karakter } \\
\text { tertentu }\end{array}$ & $\begin{array}{l}\text { Ya, penting } \\
\text { sekali } \\
\text { memiliki } \\
\text { perkataan yang } \\
\text { baik jadi tidak } \\
\text { "omdo" } \\
\text { tentunya } \\
\text { perkataanya } \\
\text { dapat } \\
\text { dipercayakan } \\
\text { dan } \\
\text { dipertanggung } \\
\text { jawabkan. }\end{array}$ & $\begin{array}{l}\text { Karena banyak } \\
\text { orang mau } \\
\text { melakukan } \\
\text { segala sesuatu } \\
\text { jika ada orang } \\
\text { sudah } \\
\text { mengerjakanny } \\
\text { a. Tingkah laku } \\
\text { yang baik akan } \\
\text { berdampak } \\
\text { baik, sebaliknya } \\
\text { tingkah laku } \\
\text { buruk akan } \\
\text { berdampak } \\
\text { buruk }\end{array}$ & $\begin{array}{l}\text { Kasih menjadi } \\
\text { dasar } \\
\text { pelayanannya. } \\
\text { Dengan kasih } \\
\text { ia bisa } \\
\text { memimpin } \\
\text { secara adil } \\
\text { artinya dia } \\
\text { tidak } \\
\text { membeda- } \\
\text { bedakan } \\
\text { orang/bawahan } \\
\text { ya. }\end{array}$ & $\begin{array}{l}\text { Karena } \\
\text { kesetiaan } \\
\text { adalah } \\
\text { bagian dari } \\
\text { integritas, } \\
\text { kesetiaan } \\
\text { diperlukan } \\
\text { di tengah } \\
\text { zaman } \\
\text { yang } \\
\text { banyak } \\
\text { tidak lagi } \\
\text { menjunjun } \\
\text { g kesetiaan. }\end{array}$ & $\begin{array}{l}\text { Karena } \\
\text { kesucian } \\
\text { merupakan } \\
\text { rekam jejak } \\
\text { seseorang } \\
\text { pemimpin } \\
\text { muda yang } \\
\text { memiliki } \\
\text { kesucian } \\
\text { berarti ia } \\
\text { sudah } \\
\text { mengenal } \\
\text { kebenaran } \\
\text { sejati di } \\
\text { dalam } \\
\text { Tuhan. }\end{array}$ \\
\hline
\end{tabular}

Tabel. 3. Pemimpin Yang Menjadi Teladan

\section{Pembahasan}

\section{Kualitas Pemimpin yang baik}

A. Berdasarkan pemahaman dari pengertian umum tentang pemimpin muda berintegritas, dapat disimpulkan bahwa, berintegritas itu adalah: a. Adanya kesamaan antara perkataan dan perbuatan. b. Memiliki tanggung jawab atas tugas yang dipercayakan. c. Kualitas bicara dengan tindakan yang sesuai. d. 
pemimpin yang konsekuen dengan apa yang dikatakan. e. Konsisten antara perkataan dan tindakan.

Dari hasil penelitian tadi di temukan bahwa pemimpin yang berintegritas adalah pemimpin yang ada keserasian antara perkataan dan tindakan, sehingga bisa menjadi teladan.

B. Pemimpin muda yang berintegritas harus memiliki intelektual yang baik.

Dari pemahaman pemimpin muda di dapatkan bahwa, kualitas intelektual yang dimiliki pemimpin menjadi dasar utama dalam kepemimpinan, karena akan di pakai untuk menjalankan roda kepemimpinan dan mengembangkan roda kepemimpinannya, serta membuat terobosan-terobosan baru.

C. Pemimpin muda yang berintegritas harus memiliki kecakapan.

Kecakapan adalah modal utama dalam kepemimpinanya. Cakap atau terampil adalah sikap atau reputasi yang dimiliki untuk menjalankan kepemimpinannya serta memecahkan masalah dalam kepemimpinanya.

D. Pemimpin muda yang berintegritas memiliki spiritualitas yang baik.

Spiritualitas adalah hubungan personal pemimpin dengan Tuhan, dan Spiritualitas juga dapat memiliki pengaruh pada gaya kepemimpinanya seseorang, jika memiliki spiritualitas baik maka akan berguna terhadap orangorang lain yang di pimpinnya juga.

Dari hasil rangkuman pemahaman dengan tujuan Alumni tentang faktor kualitas, maka dapat disimpulkan bahwa mereka dapat menjawab dan menguraikan dengan baik, terlihat tidak ada beban dalam menyampaikan jawaban.

\section{Pemimpin muda yang menjadi teladan}

A. Pemahaman pemimpin muda tentang teladan adalah,

a. Pemimpin menjadi panutan. b. Pemimpin menjadi patron. c. Pemimpin menunjukkan sikap dan perilaku yang dapat dicontoh oleh orang yang di pimpin.

B. Perkataan pemimpin harus bisa dipertanggung jawabkan dan perkataan pemimpin harus bisa dipercaya, dan bersikap melayani dengan perkataan yang dimiliki.

C. Tingkah laku, adalah tingkah laku pemimpin muda menjadi sorotan dalam kehidupannya tingkah laku merupakan reputasi dari kepribadian seorang pemimpin Kristiani.

D. Kasih, pemahaman pemimpin muda, memahami kasih sebagai modal dari dalam kepemimpinan Kristen, kasih akan menjadi karakter yang memberkati orang yang dipimpin dan tidak disakiti, akan bertindak dengan hikmat dan tidak membuat orang lain merasa sakit karna keputusanya.

E. Kesetiaan adalah perbuatan yang dimiliki pemimpin muda, kesetiaan dalam kepemimpinan akan menjadi contoh dalam argumennya. Kesetiaan menjadi bagian penting mereka kepada integritas diri dan kesetian menjadi salah satu faktor untuk menuju kesuksesan.

F. Kesucian seorang pemimpin muda, kesucian adalah kunci keberhasilan kepemimpinan, kesucian menjadikan kepemimpinan di berkati Tuhan, dan kesucian membuat orang tidak mudah jatuh dalam dosa. Kesucian menjadi pilar kepemimpinan Kristen yang utama. 
Untuk bagian kedua tentang pembahasan keteladanan hidup, maka dapat disimpulkan, sangat paham dan menguraikan dengan baik, namun terkesan ragu-ragu dalam memberikan jawaban, terkesan bahwa praktek hidup sebagai seorang pemimpin muda sebagai tantangan yang harus di atasi, agar bisa menjadi pemimpin muda yang berintegritas.

\section{SIMPULAN}

Setelah dilakukan penelitian terhadap Alumni STT Biblika Jakarta, tetang pemimpin muda yang berintegritas, setelah dikaji berdasarkan 1Timotius 4:12, tentang kualitas kepemimpinan dan keteladanan hidup dan dibandingkan dengan hasil wawancara secara langsung, maka dapat disimpulkan bahwa, tingkat pemahaman alumni sangat baik terhadap pendifinisian, dan aspek pemahaman tentang faktor kualitas kepemimpinan, namun terkesan ragu-ragu ketika menjelaskan tentang hubungan faktor kualitas dan keteladanan, hal tersebut kemungkinan dipengaruh faktor pengalaman di lapangan sebagai pemimpin muda.

\section{DAFTAR PUSTAKA}

\section{Alkitab.}

Andreas Bambang Subagyo, Pengantar Riset Kuantitaf dan Kualitatif. Bandung: Kalam Hidup, 2004.

Fuad, N. (2015). Penanaman Toleransi Beragama Pada Anak Melalui Pendidikan. Societas Dei: Jurnal Agama Dan Masyarakat, 2 (1), 252.

Irawati, Enny. Peranan Mahasiswa dan Lembaga dalam Membangun Toleransi Keragaman Budaya di Sekolah Tinggi Teologi Biblika Jakarta. Jurnal Anthropologi Sosial dan Budaya Anthropos, 6 (1), 2020

Kinloch, A. S., \& Cowie, A. P. (1995). Oxford advanced learner's dictionary (vol. 1430). Oxford university press Oxford.

LAI, Perjanian Baru Interlinier Yunani-Indonesia (Jakarta, LAI, Cetakan 2, 2004).

Lexy J. Moleong, Metodologi Penelitian Kualitatif (Bandung: PT Remaja Rosdakarya, 2013)

Luth, T (2002). Masyarakat madani: solusi damai dalam perbedaan. Mediacita

Pratiwi, A. (2017, April 28). Pengaruh Media Sosial Bagi Remaja Retrieved from https://www.kompasiana.com/amipratiwi18/5902e5578c7e61e71b2c3016/pen garuh-media-sosial-bagi-remaja

Putri, W.S.R., Nurwati, N., \& Budiarti, M (2016). Pengaruh media sosial terhadap perilaku remaja. Prosiding Penelitian dan Pengabdian kepada Masyarakat, 3(1)

Tartari, E. (2015), Benefits and risk of children and adolescent using sosial media. European Scientific Journal, 11 (13)

Witoro, Johanes, Peranan Orang Tua Terhadap Tingkat Penggunaan Media Online Remaja di Jakarta (Universitas Negeri Malang: Jurnal Inspirasi Pendidikan 9 (2), 2019.

Koresponden 1. Ardianus Hulu, Wakil Gembala, Gereja Kristen Alkitab Indonesia (GKAI) Mangga Besar

Koresponden 2. Suryanie, Majelis Gereja Santosa Asih Cempaka Putih.

Koresponden 3. Nova Dwi Kusuma, Koordinator Pemuda dan Majelis, Gereja Kristen Alkitab Indonesia (GKAI) Sunter.

Koresponden 4. Yanuar Eko Purwanto, Pendeta Muda, Gereja Bethel Indonesia (GBI) Pluit. 
Koresponden 5. Rahnuel Nazara, Gembala Jemaat, Gereja Kasih Kristus Indonesia (GKKI) Apartemen Gading Nias.

Koresponden 6. Pinus, Koordinator Ibadah, Gereja Jemaat Kristus Indonesia (GJKI) Sunter.

Koresponden 7. Labuhan Sitorus, Wakil Gembala, Gereja Kristen Alkitab Indonesia (GKAI) Tanjung Priuk. 